\title{
Cultural Adaptation of Alzheimer's Disease Assessment Scale - Cognitive Subscale (ADAS-Cog) for use in India and validation of the Tamil version for South Indian population
}

Monisha Lakshminarayanan ${ }^{1}$, Sridhar Vaitheswaran ${ }^{1 *}$, Nivedhitha Srinivasan ${ }^{1}$, Gayathri Nagarajan ${ }^{1}$, Ahalya Ganesh ${ }^{2}$, Kunnukatil S Shaji ${ }^{3}$, Mina Chandra ${ }^{4}$, Murali Krishna ${ }^{5}$, Aimee Spector ${ }^{6}$

${ }^{1}$ Dementia Care in Schizophrenia Research Foundation (DEMCARES), R/7A, North Main Road, Anna Nagar West Extension, Chennai 600101, Tamil Nadu, India

${ }^{2}$ Masters Student, Master's Degree Programme in Gender Studies, Tampere University Keskustakampus, Kalevantie 4, Tampere 33100, Finland

${ }^{3}$ Department of Psychiatry, Jubilee Mission Medical College \& Research Institute, Thrissur 680005, Thrissur, Kerala, India

${ }^{4}$ Department of Psychiatry, Centre of Excellence in Mental Health, Postgraduate Institute of Medical Education and Research (PGIMER) and Dr Ram Manohar Lohia Hospital, New Delhi, India

${ }^{5}$ Department of Research, Foundation for Research and Advocacy in Mental Health (FRAMe), Mysore, India

${ }^{6}$ Research Department of Clinical, Educational and Health Psychology, University College London (UCL), London, $U K$

*Corresponding Author: Dementia Care in Schizophrenia Research Foundation (DEMCARES), R/7A, North Main Road, Anna Nagar West Extension, Chennai 600101, Tamil Nadu, India; email: sridhar.v@scarfindia.org

Word count: 4095 (with abstract and figure captions) 
Cultural Adaptation of Alzheimer's Disease Assessment Scale - Cognitive Subscale (ADAS-Cog) for use in India and validation of the Tamil version for South Indian population

Objective: Currently no standardized tools are available in the Indian languages to assess changes in cognition. Our objectives are to culturally adapt the Alzheimer's disease Assessment Scale - Cognitive Subscale (ADAS-Cog) for use in India and to validate the Tamil version in an urban Tamil-speaking older adult population.

Methods: Two panels of key stakeholders and a series of qualitative interviews informed the cultural and linguistic adaptation of the ADAS-Cog-Tamil. Issues related to levels of literacy were considered during the adaptation. Validation of the ADAS-Cog-Tamil was completed with 107 participants - 54 cases with a confirmed diagnosis of mild-moderate dementia, and 53 age, gender, and education matched controls. Concurrent validity was examined with the Vellore Screening Instrument for Dementia (VSID) in Tamil. Internal consistency using Cronbach's alpha, sensitivity, and specificity data using the Area Under the Receiver Operating Characteristics (AUROC) curve values were computed. Inter-rater reliability was established in a sub-sample.

Results: The ADAS-Cog-Tamil shows good internal consistency ( $\alpha=0.91)$, inter-rater reliability, and concurrent validity (with VSID-Patient version: $r=-$ 0.84 and with VSID-Caregiver version: $r=-0.79$ ). A cut-off score of 13 , has a specificity of $89 \%$ and sensitivity of $90 \%$ for the diagnosis of dementia.

Conclusion: ADAS-Cog-Tamil, derived from a rigorous, replicable linguistic and cultural adaptation process involving service users and experts, shows good psychometric properties despite the limitations of the study. It shows potential for use in clinical settings with urban Tamil speaking populations. The English version of the tool derived from the cultural adaptation process could be used for further linguistic adaptation across South Asia.

Key words: ADAS-Cog; Tamil; adaptation; validation; dementia; cognition; India; South Asia 


\section{Introduction}

India has about 5 million people currently living with dementia (Kumar et al., 2020).With a rapidly increasing number of people with dementia (PwD) (Alzheimer's and Related Disorders Society of India, 2010; Prince et al., 2013) there is an urgent need for validated instruments to facilitate high-quality studies on the effectiveness of interventions for dementia in India. However, at present, a very small percentage of the population living with dementia are diagnosed and provided necessary treatment (Kumar et al., 2020). There is stigma and lack of awareness about the illness among healthcare professionals and the community alike (Dias \& Patel, 2009). There is a dearth of culturally validated tools for cognitive assessments in the Indian population that might aid the diagnostic process as well (Porrselvi, A.P. \& Shankar, V., 2017). A systematic review of validated cognitive assessments (Rosli et al., 2016) identified only 4 studies from India out of 38 in Asia and all of them were in Malayalam. The 10/66 battery of cognitive tests is the only other multidomain battery of assessments that has been validated and normed in the Tamil language (Sosa et al., 2009). It consists of the Community Screening Instrument for Dementia (CSI-D) with the animal naming verbal fluency task and the word list learning task with delayed recall from the Consortium to Establish a Registry for Alzheimer's Disease (CERAD) battery and an informant interview(Prince et al., 2003, 2007). Despite the education and culture fair properties of the 10/66 battery of cognitive tests in Tamil language, important domains of cognitive function like executive function and visuospatial praxis are not included. The absence of cut-off measures has restricted the wider use of this instrument for the diagnosis of dementia. A lack of standardized diagnostic tools as well as tools to reliably measure changes in cognition in different Indian languages and varied cultural context is a significant barrier to identify cognitive impairment and to conduct high-quality intervention studies in dementia in this subcontinent. 
The Alzheimer's Disease Assessment Scale - Cognitive subscale, has been widely adapted and validated (Rosen, Mohs, \& Davis, 1984; Zec et al., 1992). Studies indicated that the ADAS-Cog is sensitive to change in both mild and severe dementia (Stern et al., 1994; Caro et al., 2002). It has been used to measure cognitive changes in clinical trials and to assess the effects of pharmacological and non-pharmacological interventions on cognitive ability (Aguirre et al., 2013; Doody et al., 2009; Le Bars et al., 1997). Other cultural and linguistic adaptations of this tool have demonstrated good psychometric properties and the ability to discriminate cases from controls (Jemaa et al., 2017; Nogueira, Freitas, Duro, Almeida, \& Santana, 2018; S.-M. Paddick et al., 2017; Youn et al., 2002). Although efforts have been made to cross culturally validate an English version of the ADAS-Cog in Asia (Zainal et al., 2016), the vast linguistic and cultural diversity within the region makes such attempts insufficient. To our knowledge, the ADAS-Cog has not previously been validated for use in India. This study aimed to culturally adapt the ADAS-Cog for use in India and to validate in Tamil among older adults residing in Chennai- a metropolitan city of South India. The objectives of the study were:

1. To adapt the ADAS-Cog to be culturally and linguistically appropriate for use in an urban setting in India

2. To evaluate the psychometric properties of the adapted ADAS-Cog-Tamil

3. To explore the use of the Matchstick Design Test (MDT) as a replacement to the Figure Drawing Test (FDT) as well as compare its strength and cultural appropriateness to assess visuo-spatial abilities in the tool.

\section{Methods}

Sample Characteristics

Overall, 54 cases $[48.1 \%$ Alzheimer's disease $(n=26), 14.8 \%$ Vascular dementia $(n=8)$ and $31.5 \%$ mixed type $(n=17)]$ and 53 controls participated in the study. The descriptive data of 
both groups are provided in Table 1. No significant differences were found between cases and controls when compared for mean age, mean years in education, multilingualism and numbers of men and women.

$<$ Table 1>

Setting

The study was conducted in Chennai, India. The literacy rates for males and females are $93.7 \%$ and $86.64 \%$ respectively (State planning commission, 2017). The population is predominantly Tamil speaking. The number of people above the age of 60 years in Chennai is estimated at $11 \%$ (United Nations Population Fund, 2017).

\section{Description of the tool}

The ADAS-Cog is a subgroup of items from the Alzheimer's disease Assessment Scale (Rosen et al., 1984). It includes items that assess cognitive abilities - word recall, comprehension, constructional praxis, ideational praxis, word-finding, orientation, spoken language ability, and concentration. Lower scores indicate less impairment. While eight items are objectively scored based on the participants' performance in individual items (word recall, commands, constructional praxis, finding names of objects and fingers, ideational praxis, orientation, word recognition and remembering test instructions), the test-raters subjectively score four items based on their overall impression of the participants' performance (comprehension, spoken language ability, word-finding difficulties, and concentration). The tool is typically administered by a trained professional and the administration time varies between 30 to 35 minutes (Manning \& Ducharme, 2010)

\section{Cultural adaptation and translation}

Figure 1 describes the study process. 
$<$ Figure 1>

\section{English}

An expert panel of national and international stakeholders, including a researcher who previously worked on adapting the ADAS-Cog for use in Tanzania, two experienced Indian psychiatrists, three psychologists, a senior research coordinator, a professor of old age and clinical psychology, and two caregivers of people with dementia from Chennai met to culturally and linguistically adapt the tool. The panel assessed each item of the tool. The changes made following the panel discussion lead to the development of version 1 (V1) of the ADAS-Cog-India-English tool. Qualitative interviews with five normal functioning older adults aged above 60 years from Chennai with no history of psychiatric conditions or dementia were conducted. These participants were administered V1 and a topic guide with a structured set of questions seeking feedback regarding each item. The topic guide explored the appropriateness and cultural relevance of each item and had additional questions for certain items where the content or structure of the test was modified following the expert panel. For example, in addition to cultural appropriateness participants were asked if they preferred the matchstick design task or the figure drawing task as both were included in the adapted V1 of the tool. Changes recommended by the participants of the interviews were incorporated to generate version 2 (V2) of the English tool. Feedback was obtained from the participants of both the panel and qualitative interviews after which the Indian English tool was finalized. The main changes in the ADAS-Cog-India-English tool (V2) were:

- The words in the item 'Word Recall' were replaced with the Consortium to Establish a Registry for Alzheimer's Disease (CERAD) word list. The CERAD word list has been tested by the 10/66 group in India (Sosa et al., 2009) and has also been used in 
ADAS-Cog adaptation studies in other low and middle-income countries (LMIC) (S. M. Paddick et al., 2017).

- It was decided that both the geometric Figure Drawing Test (FDT) (used in the original version), and the Matchstick Design Test (MDT) (used in the other LMIC validated versions), for the "Constructional praxis" item would be used in the validation process to analyse if the two tests were comparable because it was unclear which would be more acceptable to the local population. The expert panel suggested that those with lower levels of literacy might be more comfortable with the MDT. The MDT was developed to replace graphomotor tests in populations with low levels of literacy and has shown greater acceptability and ability to differentiate cognitively impaired cases from controls (Baiyewu et al., 2005). It also has a high convergent validity with the Clock Drawing Test and high ecological validity in correlating with other symptom domains (like Activities of Daily Living) within dementia (de Paula et al., 2013). It has been successfully used as a replacement for the FDT in the ADASCog in other LMICs (S.-M. Paddick et al., 2017).

- Few items of the "Naming Objects and Fingers" item needed to be substituted with culturally appropriate alternatives. The expert panel reached a consensus on which items needed to be substituted with culturally appropriate alternatives. A list of four additional items was chosen in case additional words needed to be changed following the qualitative interviews. For example, 'mask' was difficult for qualitative interviewees to identify hence was replaced by 'battery' from this list of alternative words.

- The expert panel recommended the use of the "recognition" component of the Auditory Verbal Learning Test (AVLT), which has been standardized and validated for use among older adults in India (Tripathi, Kumar, Bharath, Marimuthu, \& 
Varghese, 2013) for the "Word Recognition" component in the adapted ADAS Cog. This test involves reading out a list of words followed by reading a separate list of words in which words from the first list have been placed amidst new words. The participants have to identify words that they have previously heard by saying 'yes' from words that they have not heard in the previous list.

\section{Tamil}

An expert in Tamil and English languages translated the adapted ADAS-Cog-India-English tool (V2) to Tamil. Another expert translated this back to English. The English V2 compared very closely to the back-translated version from Tamil. Only a few minor discrepancies were found and these were amended. An expert panel consisting of three psychiatrists, one psychologist, one caregiver of a person with dementia, and two Tamil language experts assessed the Tamil translated version to ensure that the adaptations were valid. Additional consideration was given to the language used for the instructions and items along with cultural appropriateness. The procedure for qualitative interviews $(n=5)$ was similar to the steps taken for the English tool following which the Tamil version was finalized. This was then shared with all the stakeholders involved for feedback and consensus. The content of the Tamil tool was similar to the English tool and no additional changes were made.

\section{A general note on the adaptation process}

We have conserved the underlying complexities of individual test items while making them culturally and linguistically appropriate. For example, in the Naming Objects subscale, we considered the relative frequency of the objects per the original version (Rosen et al., 1984), ensuring that they were comparable. Low-frequency items (Harmonica) were replaced with Tamil alternatives (Flute) by consensus of the expert panel. The additional four alternative 
items generated by the panel proved to be useful as normal older adults in the interviews phase had difficulty naming certain items (for example, Mask). They were replaced with items from this list (battery/cell). These adaptations were decided by expert consensus as there are no pre-existing lists of high and low-frequency words in Tamil.

Similarly, for the word recognition task, there was a pre-existing equivalent task available in India that had been standardized and validated - The AVLT (Rao, Subbakrishna, \& Gopukumar, 2004). It was deemed appropriate to use the AVLT test because it was an equivalent language appropriate task for the Word Recognition component. This was a major revision to the original word recognition item in the ADAS-Cog, which involved visual recognition (with the use of cards with the word printed on them for the participants to read aloud) along with verbal/auditory recognition. This eliminated the need to assess the visual recognition abilities of the participant. As the test was standardized already in the current population and variations in literacy levels might make it difficult to generalize the application of the test if there was a reading component to it, the expert panel decided to omit the visual presentation of the words.

Validation of Tamil version of ADAS-Cog (ADAS-Cog-Tamil)

Recruitment and Sample

The inclusion criteria for participants (both cases and controls) were:

1. Aged 60 and above

2. Tamil speaking

3. No significant vision or hearing impairment that could not be corrected

4. Residing in Chennai

Additionally, cases were included if they had: 
1. Diagnosis of DSM 5 Major Neurocognitive Disorder due to Alzheimer's disease, vascular disease or mixed dementia (Alzheimer's and vascular) (American Psychiatric Association, 2013)

2. Clinical Dementia Rating (CDR) (Morris, 1997) of 2 or below indicating mild or moderate severity of dementia

Cases were recruited from a geriatric outpatient mental health service in a non-governmental organization, Schizophrenia Research Foundation (SCARF) in Chennai from March 2019 to March 2020. An experienced geriatric psychiatrist (SV) confirmed the diagnosis of the major neurocognitive disorder according to DSM 5 criteria (American Psychiatric Association, 2013) and completed the CDR scoring. Those with Early onset Alzheimer's Disease (diagnosed or with onset of symptoms below the age of 60), Dementia in Lewy Bodies disease, Dementia in Parkinson's Disease and Fronto-temporal variants of dementia were excluded due to inability to find enough numbers under each category to adequately represent them in the sample population for the validation process.

Community-dwelling older adults including the relatives of the cases, age, and gendermatched to cases, were recruited as controls. A trained psychologist (ML) and geriatric psychiatrist (SV) screened controls against the eligibility criteria. The Vellore Screening Instrument for Dementia (VSID), a standardized cognitive screening test used in Tamil, (Stanley et al., 2009) was also administered to rule out any cognitive impairment. Authors GN, NS, and AG were trained in delivering the tool by the first author (ML) who was experienced in conducting cognitive assessments (ADAS-Cog-Tamil, VSID). The test administration process is described in Figure 2 below. 
Authors ML and NS assessed a separate pair of six cases and controls to examine inter-rater reliability. Each rater alternated between conducting the assessment and observing the entire testing process. The raters independently scored the assessments.

\section{Ethics}

The Institutional Ethics Committee at SCARF approved this study. All participants were required to provide voluntary written informed consent. For those people with dementia who could not provide written consent, assent was obtained from their caregivers.

\section{Statistical analysis}

As the data were not normally distributed (Shapiro \& Wilk, 1965), non-parametric tests were used to analyse the difference in medians between the groups. Significance tests were twotailed and the $\mathrm{p}$-value was set at 0.05 . Medians and interquartile ranges were calculated. Differences in proportions and ranks between the groups were examined by employing the Chi-square tests $\left(\chi^{2}\right)$ and Mann-Whitney U tests. Cronbach's alpha $(\alpha)$ was used to measure the internal consistency of the tool. Spearman's Rho (r) was used to analyse concurrent validity of the ADAS-Cog-Tamil scores with the VSID patient and informant versions (higher scores in VSID indicate better functioning hence would be inversely correlated with the ADAS-Cog-Tamil score), and to understand the relationships between age or education levels with the total ADAS-Cog-Tamil score. The relationship of ADAS-Cog-Tamil with gender was explored using Eta-values. Intra Class Correlation (ICC) (Two-way random model for absolute agreement) was performed to assess the inter-rater reliability. Area Under the Receiver Operating Characteristic (AUROC) curve for different cut-offs was plotted against the diagnosis of dementia as the dependent variable to measure the overall predictive 
value of the adapted ADAS-Cog-Tamil with sensitivity in the $\mathrm{x}$-axis and 1-specificity on the $\mathrm{y}$-axis. The positive predictive value (PPV) and negative predictive value (NPV) were calculated using a chi-square test for all cut-off values produced by the AUROC analysis. Youden's index (Youden, 1950) was also calculated for all the scores and the best value was selected as the cut off, The matchstick design test under the constructional praxis item was separately analysed and compared to the performance of the test with the figure-drawing test.

\section{Results}

$<$ Table 2>

There was a significant difference between cases and controls on all items of the ADAS-CogTamil (effect size for median total score: $r=-0.79$ ). The results of the Mann-Whitney U test results are presented in Table 2. ADAS-Cog-Tamil had high internal consistency $(\alpha=0.91)$ and high concurrent validity with the VSID patient version $(\mathrm{r}=-0.84 \mathrm{p}<0.001)$ as well as the informant version $(\mathrm{r}=-0.79 \mathrm{p}<0.001)$. Among both cases and controls, the ADAS-Cog-Tamil scores did not correlate significantly with age (for cases, $\mathrm{r}=0.12$, $\mathrm{p}=0.387$; for controls, $\mathrm{r}=0.232 \mathrm{p}=0.098$ ) or gender (for cases, eta $=0.13$; for controls, eta=0.31). As anticipated, the scores had a weak but significant negative correlation with educational level (for cases, $\mathrm{r}=$ $0.44 \mathrm{p}=0.001$; for controls, $\mathrm{r}=-0.43 \mathrm{p}=0.001$ ).

$<$ Table 3>

As illustrated in Table 3, internal consistency, concurrent validity, and discriminant validity were comparable for the versions of the ADAS-Cog-Tamil with the matchstick design test (MDT) and the figure-drawing test (FDT). In the qualitative interviews, all the participants preferred the matchstick design test to the figure drawing test. The expert panel also 
suggested a preference for the matchstick design test as it was deemed to be more generalizable across literacy levels and for later use in illiterate populations.

There was high inter-rater reliability for total ADAS-Cog score and all items except 'Spoken Language Ability' as shown in Table 4.

$<$ Table 4>

The AUROC analysis suggested a high discriminant validity of the tool (AUC $=0.961 ; 95 \%$ CI 0.930-0.992). At a score of 12.9 (approximately 13), the tool had optimal sensitivity (89\%) and specificity (90\%). This was also the most optimal cut off according to the Youden's Index (Youden, 1950) which was 0.79. Figure 3 displays the AUROC curve. Cut off values from the AUROC analysis with acceptable sensitivities, specificities, positive predictive value, and negative predictive values are displayed in Table 5.

$<$ Figure 3>

$<$ Table 5>

\section{Discussion}

This study aimed to culturally and linguistically adapt the ADAS-Cog for use in an urban setting in Chennai, India and evaluate its psychometric properties. The results are favourable and indicate that ADAS-Cog-Tamil is acceptable and shows sound reliability and validity for use with a South Indian Tamil speaking population. Matchstick Design Test (MDT) vs. Figure Drawing Test (FDT)

Both the expert panel and the cognitive interviewees preferred the use of the MDT to the FDT. The expert panel members agreed that for future validation exercises with low literacy 
groups, it would be beneficial to use the MDT. The participants in the qualitative interviews reported greater comfort with the MDT as opposed to the FDT. All statistical tests to evaluate the strength of the ADAS-Cog Tamil with both the FDT and MDT were in the least comparable as shown in Table 2. Hence, it was decided to retain the MDT as the main test of visuospatial abilities over the FDT for future validation with other groups as well as for clinical use.

\section{Psychometric properties}

The ADAS-Cog-Tamil has shown comparable psychometric properties to the other adaptations of the tool. The internal consistency of the tool is comparable or higher than other adaptations (Jemaa et al., 2017; Nogueira, Freitas, Duro, Almeida, \& Santana, 2018; S.-M. Paddick et al., 2017; Youn et al., 2002). Inter-rater reliability for the scale as a whole was excellent (both objectively and subjectively rated domains). Spoken Language Ability was the only item with low inter-rater reliability which is not reflected in other adaptations. This might be because of the subjective interpretation of the concept of assessing language as a whole and the difference in the experience of both raters (NS has one year of experience working with people with dementia while ML has an experience of four years). Hence this item needs to be interpreted with caution and rigorous training is advised especially for the subjectively rated domains in the tool. Standardization between raters through structured training using practical materials like videos to evaluate productive and receptive features of speech in Tamil might help reduce variations in scoring (especially of subjectively rated items) between raters. Future studies can explore this aspect of the tool in more detail. Due to the lack of validated tools in Tamil, more comprehensive evaluation of various cognitive domains could not be assessed using the VSID which is a screening tool. Other tools that have been validated in south Indian languages like Malayalam are screening tools as well (B, Swathi; V, Sreenivas; T, Manjari; N, 2015; Iype et al., 2006; Krishnan et al., 2015). The 
ADAS-Cog-Tamil showed high concurrent validity with both scales of the VSID. The psychometric properties of ADAS-Cog-Tamil are comparable to that of the VSID scales as well as other screening tools validated in South India (B, Swathi; V, Sreenivas; T, Manjari; N, 2015; Iype et al., 2006; Krishnan et al., 2015; Stanley et al., 2009). All individual items in the ADAS-Cog-Tamil were able to distinguish cases from controls $(\mathrm{p}<0.00)$. A cut-off of 13 was considered appropriate to discriminate the cases from cases and controls as it had comparable (or better) sensitivity and specificity levels to other adaptations (Jemaa et al., 2017; Nogueira et al., 2018; S.-M. Paddick et al., 2017; Youn et al., 2002).

\section{Limitations}

Though the sample size for this study was comparable to other adaptation studies of the ADAS-Cog (Jemaa et al., 2017; S. M. Paddick et al., 2017; Schultz, Siviero, \& Bertolucci, 2001), larger samples (especially to re-assess inter-rater reliability and test-retest reliability) are warranted before generalizing the findings beyond the study settings. The sample is also largely urban with lesser variability in terms of literacy compared to more rural parts of the country. The sample is also not representative of all dementia sub-types and only represents more common types of dementias like dementia in Alzheimer's disease, vascular dementia and mixed dementias. Future studies can analyse the performance of the tool with rarer forms of dementias. For the inter-rater reliability, the administrators were not blinded to the allocation status of the participants as the case participants were directly recruited from the out-patient clinic run by the institution. This was done to ensure that cases were not lost to follow up. The lack of blinding of the raters could influence the ratings, especially on the subjectively rated scales. There was also a lack of standardization in the training of the two raters as one was more experienced than the other which could potentially affect subjectively rated scores. This can be corrected in future studies by having more rigorous training structures in place for raters. The study also did not measure discriminant validity using tools 
that evaluate different constructs due to restrictions on time and resources. This can be explored in the future with larger samples.

\section{Conclusion}

ADAS-Cog-Tamil, derived from a rigorous and replicable process for linguistic and cultural adaptation involving various stakeholders including service users and experts, has good psychometric properties. It shows potential for use in clinical settings with urban Tamil speaking populations across South Asia. This will be one of the few cognitive assessment tools for dementia to be validated in Tamil in India. The English version of the tool derived from the cultural adaptation process could be used for further linguistic adaptation across South Asia. Future studies can build on this evidence with larger samples that includes rarer forms of dementias in the sample and expand the evaluation of psychometrics of the tool by assessing discriminant and ecological validity. The research team has future plans to validate an Indian English version of the tool as well as further adapt and validate the ADAS-CogTamil for rural contexts. It is also recommended that future studies explore use of the adapted English version for other South Asian communities.

\section{Author Contributions}

ML designed the study, conducted literature search, collected data, analysed data, interpreted the results and wrote the first draft of the paper. SV designed the study, interpreted results and edited and finalized the manuscript. NS, GN and AG assisted in literature search, collected and managed the data. Authors KS, MC, MK and AS were involved in designing the study, edited and finalized the manuscript. All authors were involved in preparation of the manuscript read, critically reviewed and approved the final manuscript.

Acknowledgements: We acknowledge the contribution of members of our team and the participants in the expert panels in the conduct of this study 
Sponsor (with grant number): The work was supported by the Indian Council for Medical Research (ICMR) [grant number (Indo-Foreign) 67/M/2018 NCD - I]. ICMR had no further role in the study process.

Declaration of interest: Dr. Sridhar Vaitheswaran has received speaker honorarium from Novartis, unrelated to this work. Other authors report no relevant conflict of interest.

Prior publication: The authors declare that any part of this work has not been submitted or published elsewhere 


\section{References}

A.P, Porrselvi; V., S. (2017). Status of Cognitive Testing of Adult in India. Annals of Indian Academy of Neurology, 20(4), 334-340. https://doi.org/10.4103/aian.AIAN

Aguirre, E., Hoare, Z., Streater, A., Spector, A., Woods, B., Hoe, J., \& Orrell, M. (2013). Cognitive stimulation therapy (CST) for people with dementia-who benefits most? International Journal of Geriatric Psychiatry, 28(3), 284-290.

\section{https://doi.org/10.1002/gps.3823}

American Psychiatric Association. (2013). Diagnostic and Statistical Manual of mental Disorders (DSM-5). Washington, DC: American Psychiatric Association. doi:10.1176/appi.books.9780890425596

Alzheimer's and Related Disorders Society of India. (2010). the Dementia India Report 2010. New Delhi.

B, Swathi; V, Sreenivas; T, Manjari; N, A. (2015). Dementia Assessment by Rapid Test (DART): An Indian Screening T ool for Dementia. Journal of Alzheimer's Disease \& Parkinsonism, 05(03). https://doi.org/10.4172/2161-0460.1000198

Baiyewu, O., Unverzagt, F. W., Lane, K. A., Gureje, O., Ogunniyi, A., Musick, B., ... Hendrie, H. C. (2005). The Stick Design Test: A new mensure of visuoconstructional ability. Journal of the International Neuropsychological Society, 11(5), 598-605. https://doi.org/http://dx.doi.org/10.1017/S135561770505071X de Paula, J. J., Costa, M. V., Bocardi, M. B., Cortezzi, M., De Moraes, E. N., \& MalloyDiniz, L. F. (2013). The Stick Design Test on the assessment of older adults with low formal education: evidences of construct, criterion-related and ecological validity. International Psychogeriatrics / IPA, 25(12), 2057-2065. https://doi.org/10.1017/S1041610213001282 Dias, A., \& Patel, V. (2009). Closing the treatment gap for dementia in India. Indian Journal 
of Psychiatry, 51 Suppl 1(January), S93-7.

http://www.ncbi.nlm.nih.gov/pubmed/21416026\%0Ahttp://www.pubmedcentral.nih.gov/artic lerender.fcgi?artid=PMC3038542

Doody, R. S., Ferris, S. H., Salloway, S., Sun, Y., Goldman, R., Watkins, W. E., ... Murthy, A. K. (2009). Donepezil treatment of patients with MCI: A 48-week randomized, placebo-controlled trial. Neurology.

https://doi.org/10.1212/01.wnl.0000344650.95823.03

Iype, T., Ajitha, B. K., Antony, P., Ajeeth, N. B., Job, S., \& Shaji, K. S. (2006). Usefulness of the Rowland Universal Dementia Assessment scale in South India. Journal of Neurology, Neurosurgery, and Psychiatry, 77(4), 513-514.

https://doi.org/10.1136/jnnp.2005.069005

Jemaa, S. Ben, Romdhane, N. A., Bahri-Mrabet, A., Jendli, A., Gall, D. Le, \& Bellaj, T. (2017). An Arabic Version of the cognitive subscale of the Alzheimer's Disease Assessment Scale (ADAS-Cog): Reliability, validity, and normative data. Journal of Alzheimer's Disease, 60(1), 11-21. https://doi.org/10.3233/JAD-170222

Kumar, C. S., KS, S., Varghese, M., Nair, M., George, S., Vaitheswaran, S., \& Duddu, V. (2020). Dementia in India 2020.

Krishnan, S., Justus, S., Meluveettil, R., Menon, R., Sarma, S., \& Kishore, A. (2015). Validity of Montreal Cognitive Assessment in Non-English speaking patients with Parkinson's disease. Neurology India. https://doi.org/10.4103/0028-3886.152637 Le Bars, P. L., Katz, M. M., Berman, N., Itil, T. M., Freedman, A. M., \& Schatzberg, A. F. (1997). A placebo-controlled, double-blind, randomized trial of an extract of Ginkgo biloba for dementia. Journal of the American Medical Association. https://doi.org/10.1001/jama.1997.03550160047037 Manning, C. A., \& Ducharme, J. K. (2010). Dementia Syndromes in the Older Adult. In 
Handbook of Assessment in Clinical Gerontology. https://doi.org/10.1016/B978-0-12$374961-1.10006-5$

Morris, J. C. (1997). Clinical Dementia Rating: A reliable and valid diagnostic and staging measure for dementia of the Alzheimer type. International Psychogeriatrics, 9(SUPPL. 1), 173-176. https://doi.org/10.1017/S1041610297004870

Nogueira, J., Freitas, S., Duro, D., Almeida, J., \& Santana, I. (2018). Validation study of the Alzheimer's disease assessment scale-cognitive subscale (ADAS-Cog) for the Portuguese patients with mild cognitive impairment and Alzheimer's disease. Clinical Neuropsychologist, 32(sup1), 46-59. https://doi.org/10.1080/13854046.2018.1454511 Paddick, S.-M., Kisoli, A., Mkenda, S., Mbowe, G., Gray, W. K., Dotchin, C., ... Walker, R. W. (2017). Adaptation and validation of the Alzheimer's Disease Assessment Scale Cognitive (ADAS-Cog) in a low-literacy setting in sub-Saharan Africa. Acta Neuropsychiatrica, 29(04), 244-251. https://doi.org/10.1017/neu.2016.65

Paddick, S. M., Kisoli, A., Mkenda, S., Mbowe, G., Gray, W. K., Dotchin, C., ... Walker, R. W. (2017). Adaptation and validation of the Alzheimer's Disease Assessment Scale Cognitive (ADAS-Cog) in a low-literacy setting in sub-Saharan Africa. Acta Neuropsychiatrica, 29(4), 244-251. https://doi.org/10.1017/neu.2016.65 Prince, M., Ferri, C. P., Acosta, D., Albanese, E., Arizaga, R., Dewey, M., Gavrilova, S. I., Guerra, M., Huang, Y., Jacob, K. S., Krishnamoorthy, E. S., McKeigue, P., Rodriguez, J. L., Salas, A., Sosa, A. L., Sousa, R. M. M., Stewart, R., \& Uwakwe, R. (2007). The protocols for the 10/66 dementia research group population-based research programme. BMC Public Health, 7, 165. https://doi.org/10.1186/1471-2458-7-165

Prince, M., Acosta, D., Chiu, H., Scazufca, M., \& Varghese, M. (2003). Dementia diagnosis in developing countries: A cross-cultural validation study. Lancet. https://doi.org/10.1016/S0140-6736(03)12772-9 
Rao, S. L., Subbakrishna, D. K., \& Gopukumar, K. (2004). NIMHANS neuropsychological battery manual. Bangalore: National Institute of Mental Health and Neurosciences.

Rosen, W. G., Mohs, R. C., \& Davis, K. L. (1984). A new rating scale for Alzheimer's disease. American Journal of Psychiatry, 141(11 (1356-1364),), 1356-1364.

https://doi.org/10.1176/ajp.141.11.1356

Rosli, R., Tan, M. P., Gray, W. K., Subramanian, P., \& Chin, A. V. (2016). Cognitive assessment tools in Asia: A systematic review. International Psychogeriatrics, 28(2), 189-210. https://doi.org/10.1017/S1041610215001635

Schultz, R. R., Siviero, M. O., \& Bertolucci, P. H. F. (2001). The cognitive subscale of the “Alzheimer's Disease Assessment Scale" in a Brazilian sample. Brazilian Journal of Medical and Biological Research, 34(10), 1295-1302. https://doi.org/10.1590/S0100879X2001001000009

Shapiro, S. S., \& Wilk, M. B. (1965). An Analysis of Variance Test for Normality (Complete Samples). Biometrika. https://doi.org/10.2307/2333709

Sosa, A. L., Albanese, E., Prince, M., Acosta, D., Ferri, C. P., Guerra, M., ... Stewart, R. (2009). Population normative data for the 10/66 Dementia Research Group cognitive test battery from Latin America, India and China: A cross-sectional survey. BMC Neurology, 9, 48. https://doi.org/10.1186/1471-2377-9-48

Stanley, R., Kuruvilla, A., Kumar, S., Gayathri, K., Mathews, P., Abraham, V., ... Jacob, K. S. (2009). The Vellore screening instruments and strategies for the diagnosis of dementia in the community. International Psychogeriatrics / IPA, 21(3), 539-547. https://doi.org/10.1017/S104161020900903X State planning commission. (2017). District Human Development Report - 2017. In Government of Tamil Nadu. Retrieved from http://www.spc.tn.gov.in/DHDR/Chennai.pdf 
Stern, R. G., Mohs, R. C., Davidson, M., Schmeidler, J., Silverman, J., Kramer-Ginsberg, E., ... Davis, K. L. (1994). A longitudinal study of Alzheimer's disease: Measurement, rate, and predictors of cognitive deterioration. American Journal of Psychiatry. https://doi.org/10.1176/ajp.151.3.390

Tripathi, R., Kumar, J. K., Bharath, S., Marimuthu, P., \& Varghese, M. (2013). Clinical validity of NIMHANS neuropsychological battery for elderly: A preliminary report. Indian Journal of Psychiatry, 55(3), 279-282. https://doi.org/10.4103/00195545.117149

United Nations Population Fund. (2017). Caring for Our Elders : Early Responses Caring for Our Elders : Early Responses. United Nations Population Fund 2017. 'Caring for Our Elders: Early Responses’ - India Ageing Report - 2017. UNFPA, New Delhi, India, 3. https://doi.org/10.1002/adfm.201100401

Youden, W. J. (1950). Index for rating diagnostic tests. Cancer, 3(1), 32-35. https://doi.org/10.1002/1097-0142(1950)3:1<32::AID-CNCR2820030106>3.0.CO;2-3 Youn, J. C., Lee, D. Y., Kim, K. W., Lee, J. H., Jhoo, J. H., Lee, K. U., ... Woo, J. I. (2002). Development of the Korean version of Alzheimer's Disease Assessment Scale (ADASK). Int J Geriatr Psychiatry, 17(9), 797-803. https://doi.org/10.1002/gps.699 Zainal, N. H., Silva, E., Lim, L. L., \& Kandiah, N. (2016). Psychometric properties of Alzheimer's Disease Assessment Scale-Cognitive subscale for mild cognitive impairment and mild Alzheimer's Disease patients in an Asian context. Annals Academy of Medicine Singapore, 45, 273-283.

Zec, R. F., Landreth, E. S., Vicari, S. K., Belman, J., Feldman, E., Andrise, A., ... Kumar, V. (1992). Alzheimer disease assessment scale: A subtest analysis. Alzheimer Disease and Associated Disorders. https://doi.org/10.1097/00002093-199206030-00004

Data sharing: Data available on request from the authors 
Tables

Table 1 Demographic data

\begin{tabular}{|l|c|c|c|c|c|}
\hline & $\begin{array}{c}\text { Cases } \\
(\mathbf{n = 5 3})\end{array}$ & $\begin{array}{c}\text { Control } \\
\mathbf{s}(\mathbf{n = 5 2})\end{array}$ & \multicolumn{2}{|c|}{$\chi \mathbf{2}$} & $\begin{array}{c}\mathbf{p} \\
\text { value }\end{array}$ \\
\hline Females (\%) & $29(53.7 \%)$ & $\begin{array}{c}34(64.2 \\
\%)\end{array}$ & 1.206 & 0.272 \\
\hline Multilingual (\%) & $35(64.9 \%)$ & $\begin{array}{c}33(62.2 \\
\%)\end{array}$ & \multicolumn{2}{|c|}{0.176} & 0.674 \\
\hline Median age (IQR) & & $\boldsymbol{U}$ & $\begin{array}{c}\mathbf{z -} \\
\text { score }\end{array}$ & $\begin{array}{c}\mathbf{p} \\
\text { value }\end{array}$ \\
\hline Median Education in years (IQR) & $\begin{array}{c}72.5(68- \\
80)\end{array}$ & $\begin{array}{c}72(66- \\
78)\end{array}$ & 266.000 & -1.030 & 0.303 \\
\hline
\end{tabular}


Table 2 Test measures comparing cases and controls

\begin{tabular}{|c|c|c|c|c|c|c|}
\hline Domain & $\begin{array}{l}\text { Cases } \\
(\mathrm{n}=53)\end{array}$ & $\begin{array}{c}\text { Controls } \\
(\mathrm{n}=52)\end{array}$ & $\boldsymbol{U}$ & $\begin{array}{c}\text { z- } \\
\text { score }\end{array}$ & $\begin{array}{c}\mathbf{p} \\
\text { value }\end{array}$ & $\mathbf{r}^{*}$ \\
\hline Median VSID - P score & $\begin{array}{c}9(8- \\
10.25)\end{array}$ & $13(12-14)$ & $\begin{array}{c}2673.00 \\
0\end{array}$ & 7.832 & 0.000 & 0.76 \\
\hline Median VSID - I score & $6(4.25-7)$ & $10(9-10)$ & $\begin{array}{c}2623.00 \\
0\end{array}$ & 8.128 & 0.000 & 0.79 \\
\hline \multicolumn{7}{|c|}{ Adapted ADAS-Cog Tamil } \\
\hline Median total score (IQR) & $\begin{array}{l}25.15(18 \\
2-35)\end{array}$ & $\begin{array}{l}7.05(5.8- \\
9.4)\end{array}$ & 110.000 & -8.179 & 0.000 & -0.79 \\
\hline Median word learning score (IQR) & $7(6.3-8)$ & $5(3.8-5.8)$ & 344.500 & -6.783 & 0.000 & -0.66 \\
\hline Median commands score (IQR) & $2(1-3)$ & $0(0-1)$ & 470.000 & -6.218 & 0.000 & -0.61 \\
\hline $\begin{array}{l}\text { Median constructional praxis - } \\
\text { Geometrical figures score (IQR) }\end{array}$ & $1(1-1)$ & $1(0-1)$ & 954.500 & -3.654 & 0.000 & -0.36 \\
\hline $\begin{array}{l}\text { Median constructional praxis - } \\
\text { Matchstick design score (IQR) }\end{array}$ & $1(0-3.25)$ & $0(0-0)$ & 735.500 & -5.106 & 0.000 & -0.50 \\
\hline $\begin{array}{l}\text { Median naming objects and fingers } \\
\text { score (IQR) }\end{array}$ & $1(0-1)$ & $0(0-0)$ & 568.000 & -6.356 & 0.000 & -0.62 \\
\hline $\begin{array}{l}\text { Median ideational praxis score } \\
\text { (IQR) }\end{array}$ & $1(0-2)$ & $0(0-0)$ & 544.000 & -6.169 & 0.000 & -0.60 \\
\hline Median orientation score (IQR) & $5(1.75-6)$ & $0(0-0.5)$ & 344.000 & -8.161 & 0.000 & -0.79 \\
\hline $\begin{array}{l}\text { Median word recognition score } \\
\text { (IQR) }\end{array}$ & $4(3-5.5)$ & $1(0.5-2)$ & 430.000 & -8.179 & 0.000 & -0.79 \\
\hline \multicolumn{7}{|c|}{ Subjectively Rated Items } \\
\hline $\begin{array}{l}\text { Median remembering test } \\
\text { instructions (IQR) }\end{array}$ & $1(0-4)$ & $0(0-0)$ & 682.500 & -5.711 & 0.000 & -0.55 \\
\hline Median comprehension (IQR) & $0(0-1)$ & $0(0-0)$ & $\begin{array}{c}1069.00 \\
0\end{array}$ & -3.148 & 0.002 & -0.31 \\
\hline Median word finding (IQR) & $1(0-2)$ & $0(0-0)$ & 708.000 & -5.766 & 0.000 & -0.56 \\
\hline $\begin{array}{l}\text { Median spoken language ability } \\
\text { (IQR) }\end{array}$ & $0(0-1)$ & $0(0-0)$ & 838.000 & -4.925 & 0.000 & -0.48 \\
\hline $\begin{array}{l}\text { Median Concentration and } \\
\text { distractibility (IQR) }\end{array}$ & $1(0-2)$ & $0(0-0)$ & 556.5 & -6.457 & 0.000 & -0.63 \\
\hline
\end{tabular}

ADAS-Cog, Alzheimer's Disease Assessment Scale - Cognitive; CERAD, consortium to establish a registry for Alzheimer's disease; VSID Vellore Screening Instrument for Dementia - P (patient version) - C (caregiver version); IQR, interquartile range. ${ }^{*} \mathrm{r}$ denotes effect size measure $(\mathrm{r}=\mathrm{z} / \sqrt{ } \mathrm{N})$ 
Table 3 Comparison of psychometric properties of ADAS-Cog Tamil with Matchstick Design Test versus ADAS-Cog Tamil with Figures Drawing Test

\begin{tabular}{|c|c|c|}
\hline $\begin{array}{l}\text { Psychometric } \\
\text { properties }\end{array}$ & $\begin{array}{l}\text { ADAS-Cog Tamil with } \\
\text { Matchstick Design Test }\end{array}$ & $\begin{array}{l}\text { ADAS-Cog Tamil with Figures Drawing } \\
\text { Test }\end{array}$ \\
\hline $\begin{array}{c}\text { Internal } \\
\text { consistency }\end{array}$ & $\alpha=0.910$ & $\mathrm{\alpha}=0.900$ \\
\hline $\begin{array}{c}\text { Concurrent } \\
\text { validity VSID P }\end{array}$ & $\mathrm{r}=-0.846$ & $\mathrm{r}=-0.845$ \\
\hline $\begin{array}{c}\text { Concurrent } \\
\text { validity VSID I }\end{array}$ & $\mathrm{r}=-0.790$ & $\mathrm{r}=-0.782$ \\
\hline AUC value & 0.961 & 0.958 \\
\hline Cut off & 12.95 & 13.05 \\
\hline Sensitivity & 0.889 & 0.889 \\
\hline 1-specificity & 0.096 & 0.115 \\
\hline
\end{tabular}

ADAS-Cog, Alzheimer's disease Assessment Scale - Cognitive; VSID Vellore Screening Instrument for Dementia - P (patient version) - C (caregiver version); AUC, Area Under the Curve. 
Table 4: Item-wise inter-rater reliability

\begin{tabular}{|l|l|l|l|}
\hline Item & $\begin{array}{l}\text { ICC (single } \\
\text { measures) } \\
\text { value }\end{array}$ & $\begin{array}{l}\text { 95\% } \\
\text { Confidence } \\
\text { Interval }\end{array}$ & p-value \\
\hline Word Recall & 0.99 & $0.99-1.00$ & $<0.001$ \\
\hline $\begin{array}{l}\text { Ideational } \\
\text { Praxis }\end{array}$ & 0.93 & $0.797-0.98$ & $<0.001$ \\
\hline Orientation & 0.99 & $0.98-0.99$ & $<0.001$ \\
\hline $\begin{array}{l}\text { Word } \\
\text { Recognition }\end{array}$ & 0.99 & $0.96-1.00$ & $<0.001$ \\
\hline $\begin{array}{l}\text { Remembering } \\
\text { Test } \\
\text { Instructions }\end{array}$ & 0.98 & $0.94-0.99$ & $<0.001$ \\
\hline $\begin{array}{l}\text { Spoken } \\
\text { Language } \\
\text { Ability }\end{array}$ & 0.42 & $-0.23-0.80$ & 0.088 \\
\hline $\begin{array}{l}\text { Concentration } \\
\text { and } \\
\text { Distractibility }\end{array}$ & 0.96 & $0.87-0.99$ & $<0.001$ \\
\hline
\end{tabular}


Table 5: Cut of values with sensitivity, specificities, positive as well as negative predictive values

\begin{tabular}{|r|r|r|r|r|}
\hline \multicolumn{2}{|l|}{$\begin{array}{l}\text { ADAS-Cog } \\
\text { score }\end{array}$} & \multicolumn{2}{|l|}{ Sensitivity } & \multicolumn{2}{l|}{ PPV } & \multicolumn{2}{l|}{ NPV } \\
\hline 12.45 & $88.90 \%$ & $88.50 \%$ & $88.90 \%$ & $88.50 \%$ \\
\hline $\mathbf{1 2 . 9 5}$ & $\mathbf{8 8 . 9 0 \%}$ & $\mathbf{9 0 . 4 0 \%}$ & $\mathbf{9 0 . 6 0 \%}$ & $\mathbf{8 8 . 7 0 \%}$ \\
\hline 13.65 & $85.20 \%$ & $90.40 \%$ & $90.20 \%$ & $85.50 \%$ \\
\hline 14.05 & $85.20 \%$ & $92.30 \%$ & $92.00 \%$ & $85.70 \%$ \\
\hline
\end{tabular}

ADAS-Cog, Alzheimer's disease Assessment Scale - Cognitive; PPV - Positive Predictive Value; NPV - Negative Predictive Value 


\section{Figures (Please print in colour)}

Figure1: Study Process

Figure 2: Test administration process

Figure 3: Area Under the Receiver Operating Curve for ADAS-Cog-Tamil with Matchstick Design Test and Figure Drawing Test compared with dementia diagnosis as dependent variable

Footnotes: Area Under the Curve $=0.961 ;$ Standard Error $=0.016 ; \mathrm{p}=0.000$ (95\% confidence interval $=0.930-0.992$ ) 